\title{
Antigenically dominant proteins within the human liver mitochondrial proteome identified by monoclonal antibodies
}

\author{
JU YanFang ${ }^{*}$, YANG JinJu ${ }^{2}$, LIU Rong ${ }^{2}$, LIU XiaoLan ${ }^{2}$, DU XueMei ${ }^{2}, \mathrm{LIU} \mathrm{Li}^{2}$, \\ CHEN ZhiCheng ${ }^{2}$, CHI Jun ${ }^{2}$, LIU ShuEr ${ }^{2}$, GAO Yuan ${ }^{2}$, GAO JianEn ${ }^{2}$, \\ JIAO ShunChang ${ }^{1}$, HE FuChu ${ }^{2} \&$ SUN QiHong ${ }^{2 *}$ \\ ${ }^{1}$ Department of Oncology, General Hospital of PLA, Beijing 100853, China; \\ ${ }^{2}$ State Key Laboratory of Proteomics, Beijing Proteome Research Center, Beijing Institute of \\ Radiation Medicine, Beijing 102206, China
}

Received May 7, 2010; Accepted August 26, 2010

\begin{abstract}
Analysis of the mitochondrial proteome would provide valuable insight into the function of this important organelle, which plays key roles in energy metabolism, apoptosis, free radical production, thermogenesis, and calcium signaling. It could also increase our understanding about the mechanisms that promote mitochondrial disease. To identify proteins that are antigenically dominant in human liver mitochondria, we generated $>240$ hybridoma cell lines from native mitochondrial proteins after cell fusion, screening, and cloning. Antibodies that recognized mitochondrial proteins were identified by screening human liver cDNA expression libraries. In this study, we identified 6 major antigens that were recognized by at least 2 different monoclonal antibodies (mAbs). The proteins that were antigenically dominant were: acetyl-Coenzyme A acyltransferase 2 (mitochondrial 3-oxoacyl-Coenzyme A thiolase), aldehyde dehydrogenase 1 family member A1, carbamoyl phosphate synthetase 1 , dihydrolipoamide S-acetyltransferase (E2 component of pyruvate dehydrogenase complex), enoyl coenzyme A hydratase 1, and hydroxysteroid (11-beta) dehydrogenase 1 . We also determined the subcellular localizations of these enzymes within the mitochondria using immunohistocytochemistry. We believe that these well-characterized antibodies will provide a valuable resource for the Human Liver Proteome Project (HLPP), and will make studies aimed at investigating liver mitochondrial function far easier to perform in future. Our results provide strong evidence that, (i) depletion of dominant proteins from liver mitochondrial samples is possible and, (ii) the approaches adopted in this study can be used to explore or validate protein-protein interactions in this important organelle.
\end{abstract}

mitochondria, monoclonal antibodies, cDNA library screening, antigenically dominant proteins, liver

Citation: Ju Y F, Yang J J, Liu R, et al. Antigenically dominant proteins within the human liver mitochondrial proteome identified by monoclonal antibodies. Sci China Life Sci, 2011, 54: 16-24, doi: 10.1007/s11427-010-4115-0

The mitochondrion is a highly specialized subcellular organelle. Mitochondria play many crucial and diverse roles that affect normal cellular processes as well as disease pathology. Mitochondria not only supply ATP to the cell, but also play roles in redox cell signaling [1-3], apoptotic cell

*Corresponding author (email: yanfangju@yahoo.com.cn; qihongs@vip.sina.com) signaling [4], and cellular homeostasis. Mitochondrial dysfunction is known to contribute to several human diseases, such as diabetes, cancer, neurodegeneration, and cardiovascular pathology [5-12]. Specifically, the accumulated damage caused by reactive oxygen and nitrogen species, together with binding of environmental toxins are known to contribute to the development of the more prevalent neu- 
rodegenerative disorders. These include Parkinson's, Alzheimer's, and Huntington's diseases, amyotrophic lateral sclerosis, Down's syndrome, and schizophrenia, as well as the aging process itself [13-25]. Mitochondria can also be adversely affected by cancer treatment and some chemicals have been shown to induce mitochondrial-mediated apoptosis in human cancer cells [26]. Because proteins execute mitochondrial function, researchers have traditionally paid more attention to changes in mitochondrial protein structure and function than studying mitochondrial DNA mutation in disease pathology. The identification and analysis of the mitochondrial proteome should, therefore, provide better understanding of the numerous functions of this important organelle and elucidate the mechanisms underlying mitochondrion-related diseases. Monoclonal antibodies (mAbs), with their inherently high specificities and sensitivities, are powerful tools in biological research. Antibody-based technologies (including antibody microarrays) make it possible to detect and quantitate protein expression levels in mitochondria. Furthermore, isolation of mitochondrial oxidative complexes can now be achieved using mitochondrial protein-specific antibodies [27]. To keep pace with the capabilities of the new proteomics technologies will require access to a large number of well characterized antibodies.

In earlier studies, the proteins that induce T-cell responses resulting in antibody generation were classified as antigenically dominant proteins. Identification and characterization of immunodominant proteins or immunodominant epitopes in protein mixtures is one of the most important issues in vaccine design and monoclonal antibody generation. It has been demonstrated that immunodominance, involving a B lymphocyte response, is usually limited to a small proportion of the potential determinants of a protein antigen [27]. Several aspects that appear to be involved in immunodominance have been investigated, such as processing of the antigen, peptide competition for class II presentation, and T-cell recognition of immunodominant epitopes, for example [28,29].

In this paper we generated a hybridoma bank by immunizing mice with isolated mitochondria, and fractionated mitochondrial protein mixtures which contained numerous proteins. In an earlier paper, we described the approaches taken to identify $\mathrm{mAb}$ specificity, using mass spectrometry and cDNA expression library screening [30]. Using these approaches, in this study, we identified 19 target proteins that were recognized by 244 hybridoma supernatants. Among these target proteins, six proteins were recognized by two or more hybridomas. We defined these six proteins as antigenically dominant proteins, because of their strong ability to induce antibody responses in immunized mice. These results enabled us to test the mAbs for their ability to deplete the recognized protein from liver tissue lysates. The results of these studies will guide future research aimed at generating monoclonal antibodies against the less immunodominant proteins within liver tissue.

\section{Materials and methods}

\subsection{Chemicals and liver tissue samples}

Unless otherwise indicated, all biochemicals were purchased from Sigma (St. Louis, MO, USA) or Bio-Rad (Hercules, CA, USA).

\subsection{Isolation of human liver mitochondria}

Mitochondria were isolated according to standard centrifugation procedures with minor adaption [1]. Ten grams of human liver tissue was homogenized in $40 \mathrm{~mL}$ of a buffer containing $50 \mathrm{mmol} \mathrm{L}^{-1}$ sucrose, $10 \mathrm{mmol} \mathrm{L}^{-1}$ HEPES, 1 mmol L ${ }^{-1}$ EDTA, $200 \mathrm{mmol} \mathrm{L}^{-1}$ Mannitol and protease inhibitors (Pierce, Chicago, IL, USA), pH 7.4 at $4{ }^{\circ} \mathrm{C}$. After centrifugation at $1000 \times g$ per homogenized liver, mitochondria were collected by centrifugation of the supernatant at $10000 \times g$ for $10 \mathrm{~min}$ at $4^{\circ} \mathrm{C}$. Mitochondria were re-suspended in isotonic buffer comprising $10 \mathrm{mmol} \mathrm{L}^{-1}$ Tris- $\mathrm{HCl}$ pH 7.8, $0.25 \mathrm{~mol} \mathrm{~L}^{-1}$ sucrose, $0.2 \mathrm{mmol} \mathrm{L}^{-1}$ EDTA and 0.5 mmol L ${ }^{-1}$ PMSF. Protein concentration was calculated using BCA-reagent (Pierce, Chicago, IL, USA) against a standard curve constructed using BSA. For animal immunization and $\mathrm{mAb}$ characterization, aliquots of $5 \mathrm{mg}$ mitochondria were centrifuged at $14000 \times g$ for $10 \mathrm{~min}$ at $4^{\circ} \mathrm{C}$ and the supernatants discarded. The pellets were used for immunization or frozen in liquid $\mathrm{N}_{2}$ and stored at $-80^{\circ} \mathrm{C}$ for up to 1 month.

\subsection{Preparation of mitochondrial proteins}

\subsubsection{Preparation of mitochondrial total lysates}

Mitochondria were re-suspended in $100 \mu \mathrm{L}$ isotonic buffer and $300 \mu \mathrm{L}$ of RIPA (1\% NP-40, $0.15 \mathrm{~mol} \mathrm{~L}^{-1}$ sodium chloride, $2 \mathrm{mmol} \mathrm{L}{ }^{-1}$ EDTA, $50 \mathrm{mmol} \mathrm{L}^{-1}$ sodium fluoride, 0.2 mmol L $\mathrm{L}^{-1}$ sodium orthovanadate, $0.01 \mathrm{~mol} \mathrm{~L}^{-1}$ sodium phosphate, and protease inhibitors $\mathrm{pH}$ 7.6) added and the solution incubated on ice for $30 \mathrm{~min}$. Mitochondrial proteins were obtained by recovery of the RIPA lysate supernatant after centrifugation at $14000 \times \mathrm{g}$ for $30 \mathrm{~min}$ at $4{ }^{\circ} \mathrm{C}$. Up to 8 $\mathrm{mg}$ of mitochondrial proteins could be prepared from $1 \mathrm{~g}$ of liver tissue using this method.

\subsubsection{Preparation of fractionated mitochondrial proteins}

Mitochondrial proteins were fractionated into 8 fractions according to their molecular weight, as determined by SDS-PAGE. The molecular weight ranges of the 8 fractions obtained were; fraction 1 ( $\geqslant 100 \mathrm{kD})$, fraction $2(75-100 \mathrm{kD})$, fraction $3(62-75 \mathrm{kD})$, fraction $4(50-62 \mathrm{kD})$, fraction 5 $(43-50 \mathrm{kD})$, fraction $6(37-43 \mathrm{kD})$, fraction $7(25-37 \mathrm{kD})$, fraction $8(\leqslant 25 \mathrm{kD})$. The fractionated mitochondrial proteins were recovered from SDS-PAGE gels in positions corresponding to their expected MW, and electro-eluted using 
Electro-Eluter (Bio-Rad Model 422).

\subsection{Generation and characterization of mAbs against human liver mitochondrial proteins}

Mice were immunized with $0.5-1.0 \mathrm{mg}$ of mitochondrial proteins or with isolated mitochondria particles containing equivalent amounts of the proteins. Individual mice were immunized with 100-200 $\mu \mathrm{g}$ of the 8 fractionated mitochondrial proteins. Hybridoma cells were generated following standard cell fusion and cloning procedures. Monoclonal antibodies (mAbs) were characterized by determining their antibody isotype, and their specificities towards mitochondrial proteins identified using ELISA and Western blot techniques.

\subsection{Identification of mAb specificity using cDNA expression library screening}

To determine the specific antigen recognized by each monoclonal antibody produced in this study, a $\lambda$ expression Uni-ZAPâ XR pre-made liver cDNA library (Stratagene, La Jolla, CA, USA) was screened with selected hybridoma supernatants. The screening and identification procedure were performed in accordance with the manufacturer's instructions. Briefly, the cDNA library was plated onto 150 $\mathrm{mm}$ plates at $5 \times 10^{4} \mathrm{pfu} /$ plate and nitrocellulose membranes impregnated with $10 \mathrm{mmol} \mathrm{L}^{-1}$ IPTG were used to induce cDNA expression and subsequent transfer of the proteins. Washed membranes were blocked overnight in TBST containing $1 \%$ skimmed milk at $4{ }^{\circ} \mathrm{C}$, and then incubated with primary antibody (hybridoma supernatant in blocking buffer diluted at $1: 5-1: 100$ ) for $2 \mathrm{~h}$ at $37^{\circ} \mathrm{C}$. Bound antibodies were detected using horse radish peroxidase (HRP)-conjugated goat anti-mouse IgG with the ECL detection system (Amersham Pharmacia Biotech). The plaques corresponding to each positive spot on the film were cored, and the phage particles released into TBS buffer. To verify a positive clone, a second round of membrane screening was performed by plating the released phage pool onto $150 \mathrm{~mm}$ plates at a density of $1 \times 10^{3}-3 \times 10^{3} \mathrm{pfu} /$ plate, following the same procedure as for the primary screening. At such low plating densities, individual positive clones could be readily isolated from the plates. The inserted cDNA sequences from the positive phages were transferred into a pBluescript phagemid ( $\mathrm{pBluescript} \mathrm{SK}^{+}$) for sequencing after in vivo excision following the manufacturer's instructions. A BLAST was used to interrogate the sequencing data (GenBank). Because the inserted cDNA in pBluescript $\mathrm{SK}^{+}$can be induced to express recombinant protein in Escherichia coli, SDS-PAGE and western blots were used to validate antigen expression and antigen-antibody reactions. The $E$. coli SOLR strain containing pBluescript $\mathrm{SK}^{+}$were induced using $1 \mathrm{mmol} \mathrm{L} \mathrm{L}^{-1}$ IPTG for $3 \mathrm{~h}$ at $30^{\circ} \mathrm{C}$ when cultures reached an $A_{600}$ of 0.3 . Bacterial proteins were loaded onto SDS-PAGE gels and western blotted. The SOLR strain containing an empty vector, pBluescript $\mathrm{SK}^{-}$, was used as a negative control.

\subsection{Immunohistochemistry and immunofluorescence staining}

To assess whether the mAbs produced in this study could recognize the mitochondria within liver cells, immunohistochemistry staining of liver tissues and immunofluorescent staining of liver carcinoma cells were performed. Frozen sections were fixed in dimethyl ketone for ten min at $4^{\circ} \mathrm{C}$. After washing in TBST for $5 \mathrm{~min}$, slides were incubated for $30 \mathrm{~min}$ in $3 \%$ hydrogen peroxide in methanol at room temperature to quench any endogenous peroxidase activity. After washing 3 times with TBST, the slides were blocked for $30 \mathrm{~min}$ with normal goat serum at room temperature. Primary antibodies were applied to the blocked sections and incubated overnight at $4^{\circ} \mathrm{C}$. Positive signals were visualized using diaminobenzidine tetrahydrochloride (DAB) solution, after a $20 \mathrm{~min}$ incubation of the slides at $37^{\circ} \mathrm{C}$ with HRP-labeled goat anti-mouse IgG antibody (GBI, Beijing, China). Slides were counter-stained with hematoxylin for 5 min and washed in deionized $\mathrm{H}_{2} \mathrm{O}$ for $1 \mathrm{~min}$.

Rhodamine 123 (green) was used to visualize mitochondria in live liver carcinoma cell preparations (Huh7) and $\mathrm{mAb}$ binding detected using TRITC-conjugated AffiniPure Goat Anti-Mouse IgG $(\mathrm{H}+\mathrm{L})$ (red) for double staining. Monolayer cells were cultured in RPMI 1640 containing 1 $\mu \mathrm{g} \mathrm{mL}{ }^{-1}$ Rhodamine 123 for $30 \mathrm{~min}$ at $37^{\circ} \mathrm{C}$, and the cells fixed in TBS containing 4\% paraformaldehyde and $0.2 \%$ Triton-100 for $20 \mathrm{~min}$ at $4^{\circ} \mathrm{C}$. Fixed cells were washed 3 times with $\mathrm{PBS}$ and incubated with primary antibodies overnight at $4^{\circ} \mathrm{C}$. Cells were incubated with the secondary antibody for $30 \mathrm{~min}$ at $37^{\circ} \mathrm{C}$. After washing 3 times, the slides were analyzed using fluorescence microscopy (Olympus, Tokyo, Japan).

\subsection{Depletion of antigenically dominant proteins from human liver mitochondria protein extracts}

Purified mAb BAH103 (100 $\mu \mathrm{g})$ was incubated with $100 \mu \mathrm{L}$ Protein $\mathrm{G}$ agarose suspension (Pierce) overnight at $4{ }^{\circ} \mathrm{C}$ in a total of $600 \mu \mathrm{L}$ PBS buffer. After washing 3 times with PBS, $1 \mathrm{mg}$ of the mitochondrial proteins were added to the $\mathrm{mAb}-$ ProteinG-agarose mix and incubated at $4{ }^{\circ} \mathrm{C}$ for $3 \mathrm{~h}$. Proteins that did not bind mAbs were loaded onto SDS-PAGE gels and western blotted. Proteins that did not bind mAbs were used to immunize mice to generate anti-sera.

\section{Results and discussion}

\subsection{Isolation of human liver mitochondrial proteins}

Mitochondria are one of the most important organelles for 
the maintenance of cell life. Given the contribution of mitochondria to the normal physiology and pathology of the cell, it is not surprising that this organelle contains around 1200 proteins. Although the exact number of mitochondrial proteins in mammals is not known, about 600-700 have been characterized [31]. In this study we used homogenization and standard differential centrifugation techniques to isolate mitochondria from human liver tissue, and isolated $48 \mathrm{mg}$ of mitochondrial protein from $10 \mathrm{~g}$ of liver. The isolated mitochondria were lysed, and the total mitochondrial protein content analyzed using 1D and 2D-PAGE [30], and succinate dehydrogenase activity testing (data not shown). This confirmed the purity and enrichment of the mitochondrial protein in the samples. Using PDQuest software (Ver 7.0, Bio-Rad) the MW and isoelectric point (pI) of each spot were analyzed. This revealed that the $\mathrm{MW}$ and $\mathrm{pI}$ for most of the proteins ranged between 20 and $80 \mathrm{kD}$ and $\mathrm{pH} 3-8$. These data are consistent with those obtained in previous studies of mitochondrial proteomes [3]. The MW of the most abundant proteins ranged between 30 and $80 \mathrm{kD}$ (as determined by $1 \mathrm{D}$ and 2D-PAGE). Fractionated mitochondrial proteins were analyzed using SDS-PAGE (Figure 1A). The sera of the mice immunized with the fractionated mi- tochondrial proteins were analyzed by Western blot (Figure 1B).

\subsection{Generation and characterization of mAb hybri- doma cell lines}

Antibodies, especially mAbs, are one of the most powerful tools in contemporary biological research. Analysis of cell or tissue protein profiles using antibody microarray technology, however, requires access to large quantities of well-characterized antibodies [4]. To establish a platform for large scale antibody production, we raised hybridoma cell lines from BALB/c mice immunized with mitochondrial protein mixtures isolated from human liver preparations. All of the 244 monoclonal hybridomas we established were tested for their isotypes. Isotype testing revealed that $89.8 \%$ were $\operatorname{IgG} 1,3.2 \%$ were $\operatorname{IgG} 2 \mathrm{a}$, and $4.9 \%$ were $\operatorname{IgG} 2 \mathrm{~b}$ (Table 1). These mAbs were further characterized by western blotting using the hybridoma supernatants. The data for some of these experiments are shown in Figure 2. Most $\mathrm{mAbs}$ recognized antigens located within mitochondria in the liver tissue sections and the mAbs reacted positively against such antigens, as demonstrated by the different pat-

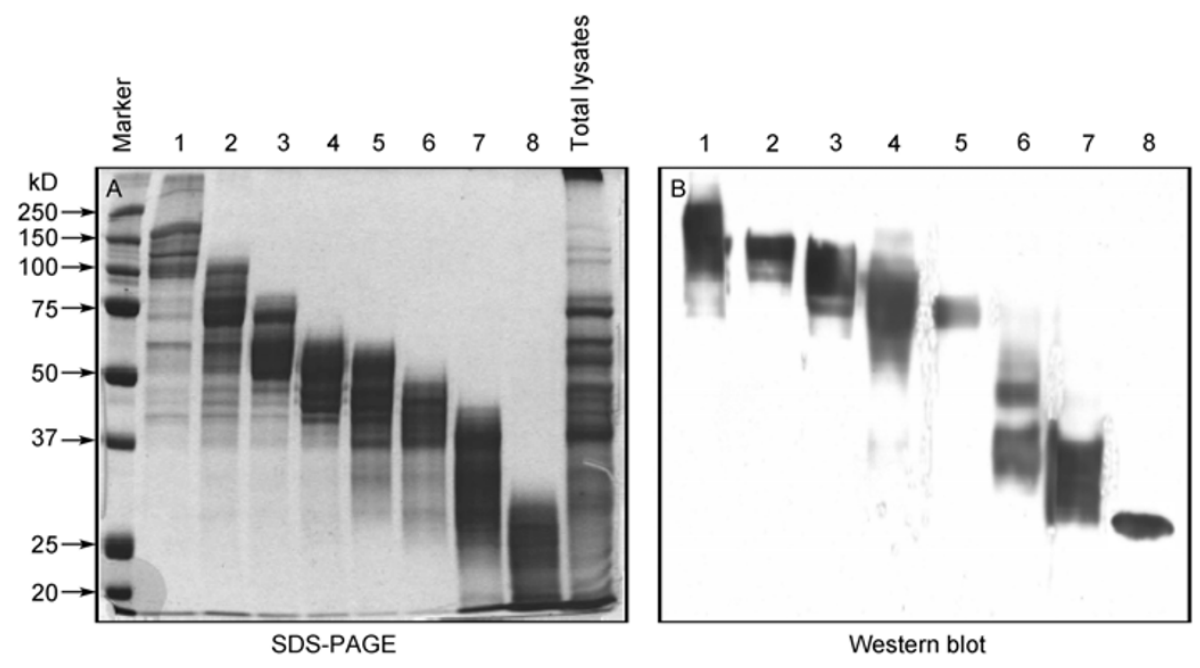

Figure 1 SDS-PAGE and Western blot analysis of fractionated mitochondrial proteins. Total mitochondrial proteins were separated on SDS-PAGE gels and electro-eluted into 8 fractions according to their molecular weights. A, Lanes 1-8: Coomassie blue stained SDS-PAGE gel showing the 8 protein fractions migrating according to their expected MWs. B, Lanes 1-8: Western blot analysis of the same fractionated proteins, illustrating the antibody staining patterns obtained using sera from mice immunized with each of the different fractions.

Table 1 mAbs against human liver mitochondria obtained by immunization with fractionated proteins

\begin{tabular}{|c|c|c|c|c|c|c|c|}
\hline \multirow[b]{2}{*}{ Immunogen } & \multirow{2}{*}{$\begin{array}{l}\text { Number of cell } \\
\text { fusion }\end{array}$} & \multirow{2}{*}{$\begin{array}{l}\text { Number of hybri- } \\
\text { doma }\end{array}$} & \multicolumn{5}{|c|}{ Class and subclass } \\
\hline & & & IgG1 & $\operatorname{IgG} 2 \mathrm{a}$ & $\operatorname{IgG} 2 b$ & IgG3 & $\operatorname{IgM}$ \\
\hline Mitochondria & 3 & 20 & 14 & 5 & 1 & 0 & 0 \\
\hline Mitochondrial proteins & 3 & 23 & 17 & 1 & 5 & 0 & 0 \\
\hline Fractionated mitochondrial proteins & 14 & 201 & 188 & 3 & 6 & 2 & 2 \\
\hline Total & 20 & 244 & $219(89.8 \%)$ & $9(3.7 \%)$ & $12(4.9 \%)$ & $2(0.8 \%)$ & $2(0.8 \%)$ \\
\hline
\end{tabular}




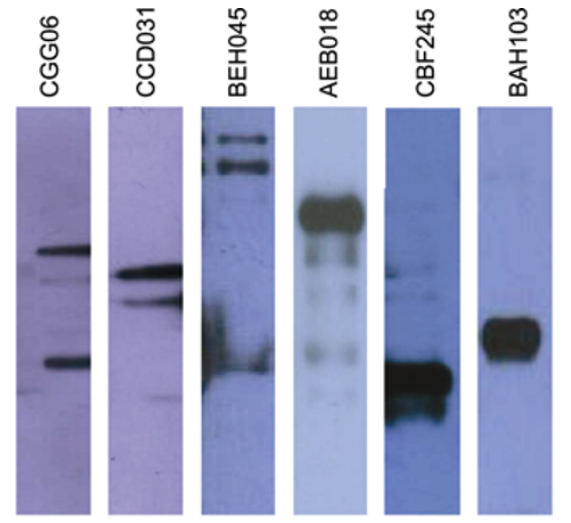

Figure 2 Mitochondrial proteins were blotted against different mAbs (i.e., hybridoma supernatants) under reduced conditions. Different mAbs patterns can be seen in Western blots of human liver mitochondrial proteins. The antigens which were recognized by the mAbs were: ALDH1A1 (lane 1), ACAA2 (lane 2), CPS1 (lane 3), DLAT (lane 4), HSD11B1 (lane 5) and ECH1 (lane 6).

terns observed on western blots (Figure 2).

\subsection{Antigen identification using a human liver cDNA expression library}

Many methods have been developed to detect antigens produced by individual bacterial colonies or phage plaques; these recombinant proteins can be identified using a primary antibody against the protein of interest. Alternatively, isolation of full length or partial protein-encoding genes from large recombinant cDNA libraries can also be achieved using antibodies. Such coding sequences can be used for large scale recombinant protein expression to facilitate functional and structural analyses of protein antigens.

In this study, 129 mAbs raised against human liver mitochondrial proteins were detected using a human liver cDNA expression library to determine the specificities of the mAbs. We identified $78 \mathrm{mAbs}$ that were specific for 10 different protein types. Six of these proteins could be classified as antigenically dominant (Tables 2 and 3) and at least 2 hybridoma cell lines could be produced for each of the six proteins. Table 2 shows the 30 hybridoma cell lines that recognize carbamoyl phosphate synthetase 1 (CPS1). The hybridoma cell lines were obtained from mice immunized with fractionated or total mitochondrial protein preparations. These results show that CPS1 is the dominant protein antigen within mitochondria. CPS1 is believed to be one of the most abundant proteins in the liver, comprising approximately $4 \%$ of the total protein content of this organ [32,33]. It is possible, therefore, that relatively high levels of this protein in the mitochondria could influence immune responses, as has been suggested previously where it was found that antigen priming was dose dependent [34].

In protein mixtures, we found that some, but not all of the most abundant proteins were antigenic, whilst some, but not all of the antigenic proteins were abundant. We also found that the number of hybridoma cell lines derived from mice immunized with the fractioned mitochondria proteins was greater than the number of hybridoma cell lines derived from mice immunized with the mitochondria protein extracts. This could indicate that the six proteins identified are antigenically dominant proteins within mixtures (across a range of different molecular weights) (Tables 2 and 3). The six proteins were more antigenic in the fractioned mitochondria preparations compared to the unfractionated material. This could be because the representation of the mitochondrial proteins in the fractioned sample was less than that of the unfractionated samples; however, each individual protein present in the fractionated samples will be present in greater quantity. Thus, following fractionation, proteins that were not found to be strongly antigenic in the unfractionated material became immunodominant. Supporting this hypothesis, the hybridoma Acetyl-Coenzyme A acyltrans-

Table 2 Antigenically dominant proteins in human liver mitochondria identified by monoclonal antibodies

\begin{tabular}{|c|c|c|c|c|c|}
\hline Antigen & MW & $\begin{array}{l}\text { Homology vs. } \\
\text { mouse }(\%)\end{array}$ & \multicolumn{2}{|c|}{ Number of hybridomas } & Immunogen \\
\hline \multirow{3}{*}{$\begin{array}{l}\text { ALDH1A1 Aldehyde dehydrogenase } 1 \text { family, } \\
\text { member A1 }\end{array}$} & \multirow{3}{*}{57} & \multirow{3}{*}{94} & \multirow{3}{*}{44} & 1 & Mitochondrial proteins \\
\hline & & & & 24 & $\begin{array}{l}\text { Fractionated mitochondrial proteins } \\
\qquad(50-62 \mathrm{kD})\end{array}$ \\
\hline & & & & 19 & $\begin{array}{l}\text { Fractionated mitochondrial proteins } \\
\qquad(43-50 \mathrm{kD})\end{array}$ \\
\hline \multirow[b]{2}{*}{ CPS1 Carbamyl phosphate synthetase 1} & \multirow[b]{2}{*}{164} & \multirow[b]{2}{*}{95} & \multirow[b]{2}{*}{30} & 3 & Mitochondrial proteins \\
\hline & & & & 27 & $\begin{array}{l}\text { Fractionated mitochondrial proteins } \\
\qquad(\geqslant 100 \mathrm{kD})\end{array}$ \\
\hline \multirow{2}{*}{$\begin{array}{l}\text { DLAT Dihydrolipoamide S-acetyltransferase } \\
\text { (E2 component of pyruvate dehydrogenase com- } \\
\text { plex) }\end{array}$} & \multirow[b]{2}{*}{70} & & \multirow[b]{2}{*}{6} & 1 & Mitochondrial proteins \\
\hline & & & & 5 & $\begin{array}{l}\text { Fractionated mitochondrial proteins } \\
\qquad(62-75 \mathrm{kD})\end{array}$ \\
\hline \multirow{2}{*}{$\begin{array}{l}\text { HSD11B1 hydroxysteroid (11-beta) dehydro- } \\
\text { genase } 1\end{array}$} & \multirow{2}{*}{32} & 78 & \multirow{2}{*}{4} & 2 & Mitochondrial proteins \\
\hline & & & & 2 & Mitochondria \\
\hline $\begin{array}{l}\text { ACAA2 Acetyl-Coenzyme A acyltransferase } 2 \\
\text { (mitochondrial 3-oxoacyl-Coenzyme A thiolase) }\end{array}$ & 42 & 87 & 3 & 3 & $\begin{array}{l}\text { Fractionated mitochondrial proteins } \\
\qquad(37-43 \mathrm{kD})\end{array}$ \\
\hline
\end{tabular}


Table 3 Anti-mitochondria protein mAbs identified by cDNA expression library screening

\begin{tabular}{|c|c|c|c|}
\hline Antigen & Hybridoma & $\begin{array}{c}\text { Number of positive } \\
\text { clones/sequenced clones }\end{array}$ & $\begin{array}{l}\text { cDNA expressed protein/Full } \\
\text { length of Protein sequence (aa) }\end{array}$ \\
\hline ALDH1A1 Aldehyde dehydrogenase 1 family, member A1 & CGG06 & $2 / 4$ & $501(1-501) / 501$ \\
\hline $\begin{array}{c}\text { ACAA2 Acetyl-Coenzyme A acyltransferase } 2 \text { (mitochon- } \\
\text { drial 3-oxoacyl-Coenzyme A thiolase) }\end{array}$ & CCD031 & $2 / 4$ & $397(1-397) / 397$ \\
\hline CPS1 Carbamyl phosphate synthetase 1 & BEH045 & $3 / 6$ & $1227(274-1500) / 1500$ \\
\hline $\begin{array}{l}\text { DLAT Dihydrolipoamide S-acetyltransferase (E2 compo- } \\
\text { nent of pyruvate dehydrogenase complex) }\end{array}$ & AEB018 & $5 / 6$ & $427(221-647) / 647$ \\
\hline HSD11B1 Hydroxysteroid (11-beta) dehydrogenase 1) & CBF245 & $3 / 6$ & $292(1-292) / 292$ \\
\hline ECH1 Enoyl Coenzyme A hydratase 1 & BAH103 & $3 / 8$ & $325(4-325) / 328$ \\
\hline
\end{tabular}

ferase 2 (mitochondrial 3-oxoacyl-Coenzyme A thiolase) (ACAA2) cell lines were only obtained from mice immunized with fractioned mitochondria proteins. These findings indicate that protein fractionation may be a good method for producing mAbs. In addition, western blot analysis of the bacteria proteins expressed from all the positive clones further demonstrates that recombinant proteins expressed by positive clones can be recognized by the corresponding hybridoma cell culture supernatants, at their expected MWs (Figure 3).

The mAb identification success rate using this approach was around 50\%; this rate might be related to factors such as the capacity of the cDNA library and the length of the inserted sequences. Because the average length of the inserts was $1.6 \mathrm{~kb}$ in the cDNA library used in this study, only partial sequences of the genes encoding proteins with large MWs were probably present in the phage library (Table 3). Furthermore, negative results will be obtained when the epitopes recognized by the mAbs are not located within the peptide expressed by the phage library. Positive clones will not be obtained either, if the mAbs recognize epitopes within a protein that require posttranslational modifications. Therefore, it is not possible to identify all mAbs using cDNA expression libraries.

In the newly published database 'Liverbase', 6789 human liver proteins were identified by mass spectrometry
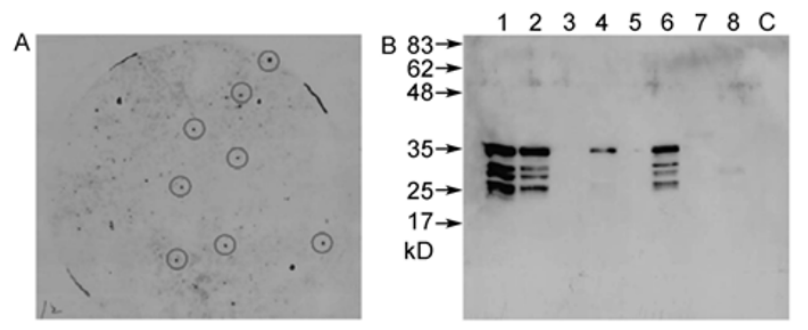

Figure 3 Characterization of mAb specificity using cDNA expression library screening. A human liver cDNA expression library was plated and the recombinant proteins expressed were transferred onto nitro cellulose membranes following induction with IPTG (Materials and methods). A, The cDNA sequences of positive plaques (red circles) recognized by $\mathrm{mAb}$ BGB095 in the Western blot were determined. The identity of the antigen was determined by BLAST analysis of GenBank. The $36 \mathrm{kD}$ protein recognized by mAb BGB095 was identified as ECH1. B, To confirm this, the expressed proteins were subjected to Western blot and SDS-PAGE analysis. The smaller antibody positive bands with MWs less that $36 \mathrm{kD}$ may be ECH1 degradation products (lane 6). that contained 2-117 unique peptides. All of the six proteins identified by the mAbs in this study are included (http:// liverbase.hupo.org.cn/liverbase/) in this database. The number of unique peptides for each protein could be an indicator of the abundance of a protein in the liver. Aldehyde dehydrogenase 1 family member A1 (ALDH1A1) was listed as protein number 3339 in the database. Only three unique peptides are associated with it in the database (the lowest number of unique peptides of all the six antigenically dominant proteins). We generated forty four hybridoma cell lines for ALDH1A1 in the present studies (the highest number of hybridoma cell lines for the six antigenically dominant proteins). Acetyl-Coenzyme A acyltransferase 2 (mitochondrial 3-oxoacyl-Coenzyme A thiolase (ACAA2) (protein number 59) was shown to contain thirty eight unique peptides (the highest number of unique peptides of the six antigenically dominant proteins). We generated only three hybridoma cell lines for ACAA2 in our study (close to the lowest number of hybridoma cell lines for the six antigenically dominant proteins). We believe that identification of the six antigenically dominant proteins recognized by our mAbs was not only affected by their relative abundance in the liver (or number of unique peptides), but also by antigenic and/or other factors such as amino acid sequence homology between the murine and human orthologues. Previous reports indicated that these six proteins have important cellular functions, some of which could be related with pathology.

CPS1, normally found in hepatocytes and small-intestine (SI) enterocytes, is the rate-limiting enzyme that catalyzes the first step of the hepatic urea cycle. Deficiency in this enzyme results in an autosomal recessive disorder associated with hyperammonemia, protein intolerance, and impaired mental and physical development. The incidence of CPS I deficiency in Japan is 1:800000 [35]. Recently, researchers found that expression of CPS1 in invasive small-intestine adenocarcinoma appears to be lost [36]. This could make this enzyme a diagnostically useful tool for identifying malignant tumors of the small-intestine.

Dihydrolipoamide acetyltransferase (DLAT) is one of six components of the mammalian pyruvate dehydrogenase complex (PDC) of the inner mitochondrial membrane. Patients with primary biliary cirrhosis (PBC; 109720), have autoantibodies against DLAT. Pyruvate dehydrogenase de- 
ficiency is a major cause of primary lactic acidosis and neurological dysfunction in infancy and early childhood. Some researchers reported patients with pyruvate dehydrogenase deficiency caused by defects in the E2 subunit. Episodic dystonia was the major neurological manifestation, with other more common features of pyruvate dehydrogenase deficiency, such as hypotonia and ataxia, being less prominent. The patients had neuroradiological evidence of discrete lesions restricted to the globus pallidus [37].

The ALDH1A1 protein is quite abundant in mouse liver [38], suggesting that a major function for this enzyme could be removal of toxic substances. There is evidence that ALDH1A1 functions downstream of alcohol dehydrogenase (ADH1) in the oxidative clearance of excess retinol through metabolism to retinoic acid (RA). ALDH1A1 plays a dominant role in the second stage of retinol clearance in adult mice. Vitamin A (retinol) is an essential nutrient for developmental regulation but is toxic in large amounts. A loss of ALDH1A1 results in accumulation of retinaldehyde produced by ADH1. Thus, ALDH1A1 may function to protect against alcohol or aldehyde toxicity in adults [39]. The enzyme is also highly expressed in non-small cell lung cancer and its downregulation is known to affect cell growth, cell motility and gene expression in lung cancer cells [40]. ALDH1A1 is also expressed at high levels in stem cells. Hematopoietic cells from Aldh1a1-deficient mice exhibit increased sensitivity to cyclophosphamide in a non-cellautonomous manner, consistent with a role in cyclophosphamide metabolism in the liver [41]. ALDH1A1 is also associated with resistance to cyclophosphamide (CP) and its derivatives [42]. Interestingly, polymorphisms in ALDH1A1 are correlated with an increased risk of liver toxicity [43].

ACAA2 is involved in $\beta$-oxidation of fatty acids. Fatty acids are important metabolic fuels, particularly at times of stress or fasting. They are predominantly metabolized in mitochondria, by a process requiring activation, transport into the mitochondria, and subsequent conversion to acetyl-CoA by $\beta$-oxidation. This sequence of events may be impaired by genetic or environmental factors. A number of patients have been identified with defects in mitochondrial fatty acid oxidation. The clinical features in these patients include hypoketotic hypoglycemic coma, sudden infant death syndrome, Reye-like episodes, muscle weakness, and cardiomyopathy [44]. Researchers found ACAA2 could attenuate the apoptotic effects of BNIP3 in two human cell lines [45].

$\mathrm{ECH} 1$ is the second enzyme in the $\beta$-oxidation pathway. Down-regulation of ECH1 activity is correlated with resistance of B-CLL (B-cell chronic lymphoid leukemia) cells to DNA damage-induced apoptosis. In this study, 13 genes were found to be specific for all resistant B-CLL cell samples, all of which were down-regulated, including ECH1 [46].

Hydroxysteroid (11-beta) dehydrogenase 1 (HSD11B1), plays an important role in regulating cortisol availability in target tissues. The enzyme is a primary regulator catalyz- ing the reduction of inactive cortisone to active cortisol. Glucocorticoid excess promotes visceral obesity and cardiovascular disease. Ligand availability to the glucocorticoid receptor is controlled by HSD11B, which also plays a crucial role in the pathogenesis of obesity and controls glucocorticoid action in inflammation. Expression of HSD11B1 was found to be significantly elevated in inflamed tissue compared to non-inflamed colon tissue [47]. Several studies have indicated that HSD11B1 plays a crucial role in the onset of type 2 diabetes. Glucocorticoid action is linked to the development of obesity and insulin resistance. Recently, inhibition of HSD11B1 has been proposed as a strategy to suppress glucocorticoid action in a tissue-specific manner [48]. There is also preliminary evidence supporting an association of HSD11B1 with osteoporosis in postmenopausal women [49]. In this case, increased HSD11B1 expression in fibroblasts could be a mechanism for increasing local cortisol levels in membranes, which could potentiate the osteolytic process through inhibition of osteoblastic function [50].

Studies on the induction of hepatic HSD11B1 in patients with alcoholic liver disease have shown mRNA expression of the enzyme was increased fivefold in the alcoholic liver disease (ALD) group compared with normal controls. These results show that significant induction of HSD11B1 gene expression and activity occurs in patients with ALD during short- and long-term abstinence from alcohol. The mechanism underlying this is unknown, but might be explained on the basis of alcohol-induced changes in intracellular redox potential, or as a protective mechanism to limit liver inflammation and injury. Selective HSD11B1 inhibitors may offer a novel therapeutic approach to treat alcoholic pseudo-Cushing's syndrome [51].

\subsection{Subcellular localization of antibody-antigens com- plexes}

To detect the antigens recognized by mAb localization in liver tissue, liver tissue slides were stained with selected mAbs and analyzed using fluorescence immunohistochemistry. The results showed that all mAbs had similar dotted staining patterns which localized in the cytoplasm (Figure 4A). To demonstrate that the characteristic dotted staining was mitochondrial in origin, a double staining assay was performed. In these experiments, Rhodamine 123, (a green mitochondrial stain) and red TRITC conjugated goat anti-mouse IgG co-localized in the cytoplasm of the liver cells (Figure 4B, yellow). Hence, the mAbs generated in this study will provide useful tools as mitochondrial markers, and for labeling or isolating mitochondria.

\subsection{Depletion of antigenically dominant proteins from human liver mitochondrial proteins}

The successful purification and identification of low abun- 
A

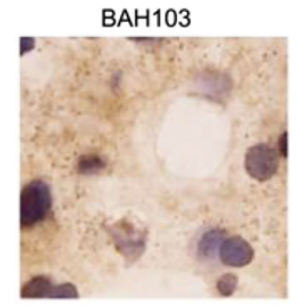

B

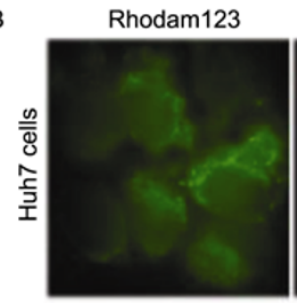

$\mathrm{BAH} 103$

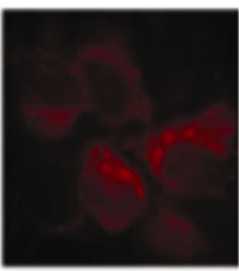

Merged

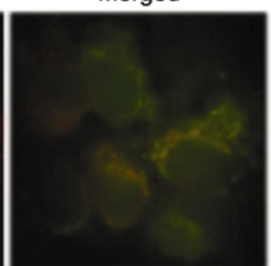

Figure 4 Immunohistochemistry staining of liver tissue samples was performed to analyze the distribution of the antigens recognized by selected mAbs in the liver tissue samples. Frozen sections were stained by mAb BAH103. A, mAb BAH103 recognition of brown particles within the cytoplasm of the liver cells. B, Double immunofluorescence staining was performed to determine whether mAb BAH103 and the mitochondria indicator Rhodamine 123 strain co-localize in the mitochondria. Mitochondria were visualized by staining a human liver carcinoma cell line (Huh7) with the mitochondria-specific marker Rhodamine 123 (green). The same slide was counter-stained with mAb BAH103 and TRITC labeled Goat anti-Mouse IgG as the second antibody (red) using indirect immunofluorescence. The merged section (yellow) shows mAb BAH103 and Rhodamine 123 co-localization within mitochondrial cells.

dance proteins is currently a significant challenge in proteomic research. Depletion of highly abundant proteins from proteomic samples is a commonly used strategy to enrich low abundance proteins. In the present study, native proteins of unknown identity were used to immunize mice and generate mAbs that could be used to recognize native proteins in human liver samples (as described in Materials and methods). As expected, antibodies against some proteins that were relatively abundant and immunodominant in the mixtures were generated. Antibody specificity was determined using an established antibody specificity identification platform. The mAbs were found to be highly effective at depleting their cognate proteins from the liver samples. In these experiments, we used a new mAb designated BAH103, to deplete ECH1 from human liver mitochondria protein samples using immunoprecipitation (IP). No positive bands were observed in the BAH103 depleted liver lysates, as determined by western blot analysis, indicating that ECH1 had been successfully depleted from the samples (Figure 5B). ECH1 depleted protein preparations were used to immunize mice. Western blots using the antiserum obtained revealed an absence of bands at positions corresponding to the molecular weight of ECH1 (Figure 5A and B). Other mAbs, such as BEH045, which was raised against CPS1 (one of the antigenically dominant proteins in liver mitochondria), were used to isolate enzymatic complexes from human liver mitochondria. These mAbs were also be used to deplete their corresponding antigen from human liver mitochondrial protein using IP [30]. These results provide strong impetus to generate mAbs against the less abundant or less immunodominant proteins present in liver samples. This can be achieved using liver samples where the immunodominant proteins are first depleted.

\section{Conclusion}

In conclusion, monoclonal antibodies against highly abundant or dominant liver mitochondrial proteins can be raised by immunizing mice with fractionated human liver mitochondrial proteins. Such mAbs have great potential to be-
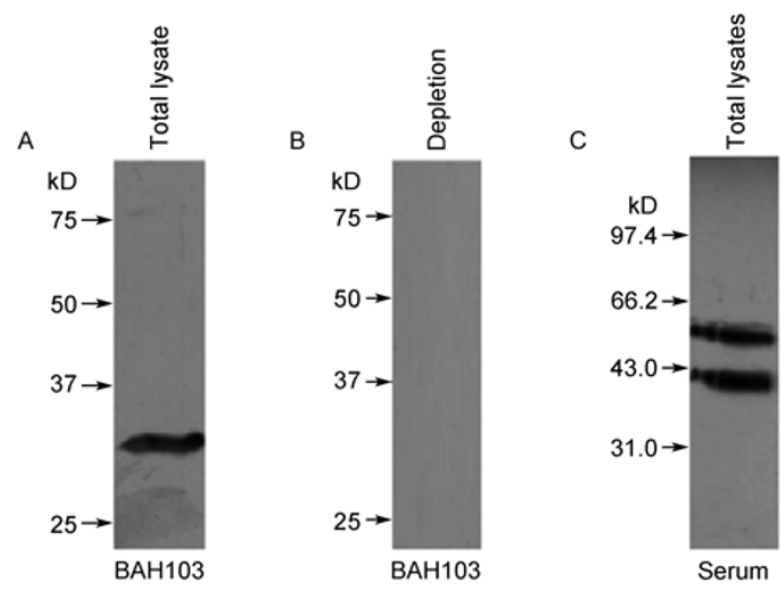

Figure 5 Depletion of antigenically dominant proteins from human liver mitochondria. A, Mitochondrial protein lysates were blotted with mAb BAH103 under the reduced condition and a positive band was observed. B, Protein lysates depleted by mAb BAH103 were blotted with mAb BAH103. No positive bands were observed. $\mathrm{C}$, When the mitochondrial proteins were blotted with serum from a mouse immunized with BAH103 depleted protein preparation, no positive band at the position corresponding to BAH103 was observed. This result indicates that BAH103 was successfully depleted from the mitochondria protein sample.

come powerful tools for in vitro mitochondrial labeling or depletion of dominant proteins from liver samples.

This work was supported by the National Basic Research Program of China (Grant No. 2006CB910803) and the National High Technology Research and Development Program of China (Grant No. 2006AA02A311).

1 Darley-Usmar V M, Rickwood D, Wilson M T. Mitochondria: a Practical Approach. Oxford: IRL Press, 1987

2 Cordwell S J, Wilkins M R, Cerpa-Poljak A, et al. Cross-species identification of proteins separated by two-dimensional gel electrophoresis using matrix-assisted laser desorption ionisation/time-of-flight mass spectrometry and amino acid composition. Electrophoresis, 1995, 16: 438-443

3 Taylor S W, Fahy D, Zhang B, et al. Characterization of the human heart mitochondrial proteome. Nat Biotechnol, 2003, 21: 281-286

4 Kusnezow W, Hoheisel J D. Antibody microarrays: promises and problems. Biotechniques, 2002, Suppl: 14-23

5 Lemasters J J, Qian T, Bradham C A, et al. Mitochondrial dysfunction in the pathogenesis of necrotic and apoptotic cell death. J Bio- 
energ Biomembr, 1999, 31: 305-319

6 Beal M F. Energetics in the pathogenesis of neurodegenerative diseases. Trends Neurosci, 2000, 23: 298-304

7 Chinnery P F, Howell N, Andrews R M, et al. Mitochondrial DNA analysis: polymorphisms and pathogenicity. J Med Genet, 1999, 36: 505-510

8 Parrella P, Xiao Y, Fliss M, et al. Detection of mitochondrial DNA mutations in primary breast cancer and fine-needle aspirates. Cancer Res, 2001, 61: 7623-7626

9 Hibi K, Nakayama H, Yamazaki T, et al. Mitochondrial DNA alteration in esophageal cancer. Int J Cancer, 2001, 92: 319-321

10 Simonnet H, Alazard N, Pfeiffer K, et al. Low mitochondrial respiratory chain content correlates with tumor aggressiveness in renal cell carcinoma. Carcinogenesis, 2002, 23: 759-768

11 Copeland W C, Wachsman J T, Johnson F M, et al. Mitochondrial DNA alterations in cancer. Cancer Invest, 2002, 20: 557-569

12 Modica-Napolitano J S, Singh K K. Mitochondrial dysfunction in cancer. Mitochondron, 2004, 4: 755-762

13 Leonard J V, Schapira A H. Mitochondrial respiratory chain disorders II: eurodegenerative disorders and nuclear gene defects. Lancet, 2000, 355: 389-394

14 Leonard J V, Schapira A H. Mitochondrial respiratory chain disorders I: mitochondrial DNA defects. Lancet, 2000, 355: 299-304

15 DiMauro S, Bonilla E, Davidson M, et al. Mitochondria in neuromuscular disorders. Biochim Biophys Acta, 1998, 1366: 199-210

16 Zeviani M, Spinazzola A, Carelli V. Nuclear genes in mitochondrial disorders. Curr Opin Genet Dev, 2003, 13: 262-270

17 Mizuno Y, Ohta S, Tanaka M, et al. Deficiencies in Complex I subunits of the respiratory chain in Parkinson's disease. Biochem Biophys Res Commun, 1989, 163: 1450-1455

18 Schapira A H, Cooper J M, Dexter D, et al. Mitochondrial complex I deficiency in Parkinson's disease. J Neurochem 1990, 54: 823-827

19 Betarbet R, Sherer T B, MacKenzie G, et al. Chronic systemic pesticide exposure reproduces features of Parkinson's disease. Nat Neurosci, 2000, 3: 1301-1306

20 Kim S H, Vlkolinsky R, Cairns N, et al. The reduction of NADH: Ubiquinone oxidoreductase 24- and 75-kD subunits in brains of patients with Down syndrome and Alzheimer's disease. Life Sci, 2001, 68: 2741-2750

21 Arenas J, Campos Y, Ribacoba R, et al. Complex I defect in muscle from patients with Huntington's disease. Ann Neurol, 1998, 43: 397-400

22 Vielhaber S, Kunz D, Winkler K, et al. Mitochondrial DNA abnormalities in skeletal muscle of patients with sporadic amyotrophic lateral sclerosis. Brain, 2000, 123: 1339-1348

23 Vielhaber S, Schroder R, Winkler K, et al. Defective mitochondrial oxidative phosphorylation in myopathies with tubular aggregates originating from sarcoplasmic reticulum. J Neuropathol Exp Neurol, 2001, 60: 1032-1040

24 Dror N, Klein E, Karry R, et al. State-dependent alterations in mitochondrial complex I activity in platelets: A potential peripheral marker for schizophrenia. Mol Psychiatry, 2002, 7: 995-1001

25 Lenaz G, D’Aurelio M, Merlo Pich M, et al. Mitochondrial bioenergetics in aging. Biochim Biophys Acta, 2000, 1459: 397-404

26 Ling Y H, Lin R, Perez-Soler R. Erlotinib induces mitochondrialmediated apoptosis in human H3255 non-small-cell lung cancer cells with epidermal growth factor receptorL858R mutation through mitochondrial oxidative phosphorylation-dependent activation of BAX and BAK. Mol Pharmacol, 2008, 74: 793-806

27 Murray J, Zhang B, Taylor S W, et al. The subunit composition of the human NADH dehydrogenase obtained by rapid one-step immunopurification. J Bio Chem, 2003, 278: 13619-13622

28 Sercarz E E, Lehmann P V, Ametani A, et al. Dominance and crypticity of $\mathrm{T}$ cell antigenic determinants. Annu Rev Immunol, 1993, 11: 729-766

29 Wienhold W, Malcherek G, Jung C, et al. An example of immunodominance: engagement of synonymous TCR by invariant CDR3 $\beta$. Int Immunol, 2000, 12: 747-756
30 Gao J, Gao Y, Ju Y, et al. Proteomics-based generation and characterization of monoclonal antibodies against human liver mitochondrial proteins. Proteomics, 2006, 6: 427-437

31 Mootha V K, Bunkenborg J, Olsen J V, et al. Integrated analysis of protein composition, tissue diversity, and gene regulation in mouse mitochondria. Cell, 2003, 115: 629-640

32 Lusty C J. Carbamoylphosphate synthetase I of rat liver mitochondria: Purification, properties, and polypeptide molecular weight. Eur J Biochem, 1978, 85: 373-383

33 Raymond Y, Shore G C. Biogenesis of the mitochondrial enzyme, carbamyl phosphate synthetase: Appearance during fetal development of rat liver and rapid repression in freshly dispersed hepatocytes. Biochim Biophys Acta, 1981, 656: 111-119

34 Saarelainen S, Zeiler T, Rautiainen J, et al. Lipocalin allergen Bos d 2 is a weak immunogen. Int Immunol, 2002, 14: 401-409

35 Nagata N, Matsuda I, Qyanagi K. Estimated frequency of urea cycle enzymopathies in Japan. Am J Med Genet, 1991, 39: 228-229

36 Cardona D M, Zhang X, Liu C. Loss of carbamoyl phosphate synthetase I in small-intestinal adenocarcinoma. Am J Clin Pathol, 2009, 132: 877-882

37 Head R A, Brown R M, Zolkipli Z, et al. Clinical and genetic spectrum of pyruvate dehydrogenase deficiency: Dihydrolipoamide acetyltransferase (E2) deficiency. Ann Neurol, 2005, 58: 234-241

38 Haselbeck R J, Hoffmann I, Duester G. Distinct functions for Aldh1 and Raldh2 in the control of ligand production for embryonic retinoid signaling pathways. Dev Genet, 1999, 25: 353-364

39 Molotkov A, Duester G. Genetic evidence that retinaldehyde dehydrogenase Raldh1 (Aldh1a1) functions downstream of alcohol dehydrogenase Adh1 in metabolism of retinol to retinoic acid. J Biol Chem, 2003, 278: 36085-36090

40 Moreb J S, Baker H V, Chang L J, et al. ALDH isozymes downregulation affects cell growth, cell motility and gene expression in lung cancer cells. Mol Cancer, 2008, 7: 87

41 Levi B P, Yilmaz O H, Duester G, et al. Aldehyde dehydrogenase 1a1 is dispensable for stem cell function in the mouse hematopoietic and nervous systems. Blood, 2009, 113: 1670-1680

42 Moreb J S, Mohuczy D, Ostmark B, et al. RNAi-mediated knockdown of aldehyde dehydrogenase class-1A1 and class-3A1 is specific and reveals that each contributes equally to the resistance against 4-hydroperoxycyclophosphamide. Cancer Chemother Pharmaco, 2007, 59: 127-136

43 Ekhart C, Rodenhuis S, Smits P H, et al. Relations between polymorphisms in drug-metabolising enzymes and toxicity of chemotherapy with cyclophosphamide, thiotepa and carboplatin. Pharmacogenet Genom, 2008, 18: 1009-1015

44 Jackson S, Kler R S, Bartlett K, et al. Combined enzyme defect of mitochondrial fatty acid oxidation. J Clin Invest, 1992, 90: 1219-1225

45 Cao W, Liu N, Tang S, et al. Acetyl-Coenzyme A acyltransferase 2 attenuates the apoptotic effects of BNIP3 in two human cell lines. Biochim Biophys Acta, 2008, 1780: 873-880

46 Vallat L, Magdelénat H, Merle-Béral H, et al. The resistance of B-CLL cells to DNA damage-induced apoptosis defined by DNA microarrays. Blood, 2003, 101: 4598-4606

47 Stegk J P, Ebert B, Martin H J, et al. Expression profiles of human 11 beta-hydroxysteroid dehydrogenases type 1 and type 2 in inflammatory bowel diseases. Mol Cell Endocrinol, 2009, 301: 104-108

48 Hale C, Wang M. Development of 11beta-HSD1 inhibitors for the treatment of type 2 diabetes. Mini Rev Med Chem, 2008, 8: 702-710

49 Hwang J Y, Lee S H, Kim G S, et al. HSD11B1 polymorphisms predicted bone mineral density and fracture risk in postmenopausal women without a clinically apparent hypercortisolemia. Bone, 2009, 45: 1098-1103

50 Tashjian R Z, Lin C, Aswad B, et al. 11beta-hydroxysteroid dehydrogenase type 1 expression in periprosthetic osteolysis. Orthopedics, 2008, 31: 545

51 Ahmed A, Saksena S, Sherlock M, et al. Induction of hepatic 11 beta-hydroxysteroid dehydrogenase type 1 in patients with alcoholic liver disease. Clin Endocrinol (Oxf), 2008, 68: 898-903

Open Access This article is distributed under the terms of the Creative Commons Attribution License which permits any use, distribution, and reproduction in any medium, provided the original author(s) and source are credited. 